\title{
Two New Species of the Henicopid Centipede Henicops (Chilopoda: Lithobiomorpha) from Queensland and Victoria, With Revision of Species from Western Australia and a Synoptic Classification of Henicopidae
}

\author{
Lauren M. Hollington ${ }^{1}$ And Gregory D. EdgeCOMBE ${ }^{2 *}$ \\ ${ }^{1}$ School of Biological Sciences, University of Sydney NSW 2006, Australia \\ lmhollington@bigpond.com \\ ${ }^{2}$ Australian Museum, 6 College Street, Sydney NSW 2010, Australia \\ greged@austmus.gov.au
}

\begin{abstract}
Henicops Newport, 1844, is the most commonly recorded Australian genus of Henicopidae, the main southern temperate clade in Lithobiomorpha. Henicops is widespread throughout eastern and southwestern Australia and New Zealand, and is represented in New Caledonia by $H$. brevilabiatus (Ribaut, 1923) n.comb. New species are $H$. tropicanus n.sp. from northeastern Queensland and $H$. milledgei n.sp. from Victoria. The two nominal species from the southwest of Western Australia, $H$. dentatus Pocock, 1901a, and H. oligotarsus Attems, 1911, are synonymous, this species being distinguished from the Queensland H. tropicanus by details of the mandibular gnathal edge and female gonopod. Other characters used for diagnosing species and supraspecific groups within Henicops include the segmentation of the tarsi, tergite shape, and the position of the Tömösváry organ. All species of Henicopidae are listed with synonymies, generic assignments and geographic occurrences.
\end{abstract}

Hollington, Lauren M., \& Gregory D. Edgecombe, 2004. Two new species of the henicopid centipede Henicops (Chilopoda: Lithobiomorpha) from Queensland and Victoria, with revision of species from Western Australia and a synoptic classification of Henicopidae. Records of the Australian Museum 56(1): 1-28.

The lithobiomorph genus Henicops Newport, 1844, is one of Australia's most commonly found centipede taxa, with abundant records through all eastern states and southwestern Western Australia, as well as a broad distribution in New Zealand. Despite its abundance, systematic work on Henicops has been limited to brief descriptions of four named species.

Excluding those species that were transferred to Lamyctes Meinert, 1868, after that genus was established, the nominal species of Henicops are the type, H. maculatus Newport, 1844, H. impressus Hutton, 1877, H. dentatus Pocock, $1901 \mathrm{a}$, and H. oligotarsus Attems, 1911. Henicops

* author for correspondence maculatus was established for Tasmanian material, and the species has also been recorded from New Zealand, Victoria and New South Wales (Pocock, 1901a; Chamberlin, 1920; Archey, 1917, 1937). Henicops impressus, described from Dunedin and Queenstown, New Zealand, is considered a synonym of $H$. maculatus, which is widespread and common in New Zealand (Archey, 1937). Henicops dentatus was erected for specimens from Perth, Western Australia, and $H$. oligotarsus from various sites in southwestern Western Australia. The possible synonymy of these Western Australian species was suggested by Archey (1937: 75). The most recent taxonomic work on Henicops is Archey's www.amonline.net.au/pdf/publications/1392_complete.pdf 